\title{
General Engineering Plus: Creating Community in a Flexible yet Technical Engineering Degree
}

\section{Dr. Malinda S. Zarske, University of Colorado, Boulder}

Malinda Zarske is the Engineering Master Teacher for the General Engineering Plus program at the University of Colorado Boulder. A former high school and middle school science and math teacher, she has advanced degrees in teaching secondary science from the Johns Hopkins University and in civil engineering from CU-Boulder. Dr. Zarske teaches engineering design in First-Year Engineering Projects and Engineering Projects for the Community, a sophomore-level course focusing on humanitarian engineering. In addition, she teaches STEP 1 and STEP 2 education courses through CU Teach Engineering, a new General Engineering Plus program specifically designed to prepare students to earn a secondary math or science teacher licensure through engineering. She manages and mentors graduate and undergraduate engineering Fellows who teach in local K-12 classrooms through the Integrated Teaching and Learning Program's TEAMS initiative, is on the development team for the TeachEngineering digital library, and is faculty advisor for CU-Boulder's Society of Women Engineers (SWE).

\section{Jaclyn L. Cunitz, University of Colorado Boulder}

Jaclyn L. Cunitz is an undergraduate student in the department of General Engineering at the University of Colorado Boulder. Her emphasis is Aerospace Engineering and her concentration is Business.

\section{Marissa H. Forbes, University of Colorado, Boulder}

Marissa H. Forbes is a doctoral candidate in civil engineering at the University of Colorado, Boulder with an engineering education research focus. She previously taught middle school science and engineering and wrote K-12 STEM curricula while an NSF GK-12 graduate engineering fellow at CU. With a master's degree in civil engineering she went on to teach advanced placement and algebra-based physics for the Denver School of Science and Technology (DSST), where she also created and taught a year-long, design-based DSST engineering course for seniors. Before beginning her PhD work, Marissa returned to $\mathrm{CU}$, where she supervised K-12 fellows and worked with educators engaged in the creation of K-12 engineering curriculum for the TeachEngineering digital library.

\section{Dr. Jacquelyn F. Sullivan, University of Colorado-Boulder}

Jacquelyn Sullivan is founding co-director of the General Engineering Plus degree program in the University of Colorado Boulder's College of Engineering and Applied Science. The newly-launched, designbased, flexible GE+ engineering degree was initially created as the "home" for CU Teach Engineering, a unique initiative to produce secondary science or math teachers through a design-based engineering degree-with the ultimate goal of broadening participation among those who attend engineering college. Sullivan was conferred as an ASEE Fellow in 2011 and was awarded NAE's 2008 Gordon Prize for Innovation in Engineering and Technology Education. 


\section{General Engineering Plus: Creating Community in a Flexible yet Technical Engineering Degree}

\section{Introduction}

Belonging to a learning community is an important part of the undergraduate student experience. Specific to engineering undergraduate programs, learning communities can help to foster group identity, program cohesiveness and program uniqueness. ${ }^{1}$ Learning communities are also linked to beneficial educational outcomes, including increased retention rates of first-year engineering students, higher first-year GPAs, and lower incidence of academic probation. ${ }^{2}$

A query of engineering undergraduate students at the University of Colorado Boulder revealed a strong desire for flexibility within their undergraduate degree program to incorporate interests internal and external to engineering. Support for the adoption of a multidisciplinary general engineering degree was strong among these students, including a large percentage of female and minority students. With the intent to broaden participation of students who stay the course in engineering degrees, $\mathrm{CU}$ Boulder piloted a new, flexible design-based undergraduate engineering degree program described in this study.

The General Engineering Plus (GE+) program facilitates significant curricular choice and customizability for students, allowing for a deep dive into both an engineering discipline and concurrent study in a complementary subject. Comprehensive degree requirements include a design-based engineering core with the choice of a "traditional" engineering emphasis including mechanical, aerospace, civil, environmental, architectural or electrical engineering coupled with a customizable concentration, such as secondary STEM teacher licensure, economics, environmental policy or a world language. Additionally, this degree integrates handson design experiences throughout the four years, nurturing a solid foundation of professional skills, such as teamwork and innovation.

This research aims to discover if and how a learning community and group identity can be formed between engineering students with diverse career interests enrolled in a new, designbased multidisciplinary engineering degree program at a large public highly research-active university. Initial data indicates that students in this new GE+ degree program are still finding each other and forming their community. Using mixed-methods analysis informed by education research — including surveys and small focus groups — we explore the ways in which community is nurtured and hindered amongst the first-year and returning students enrolled in the new engineering program. The analysis also considers which potential community-building activities and engineering undergraduate degree program characteristics are most valuable to students. Finally, recommendations are made on how to nurture community development and learning communities for students in multidisciplinary engineering programs.

\section{Background}

The act of forming a community within a new and intentionally multidisciplinary engineering undergraduate major is not well understood. A working definition of a learning community was established by reviewing the literature and applying that knowledge to the new GE+ program. 
Several definitions of learning community within academic settings exist. Gabelnick, MacGregor, Matthews and Smith choose a perspective on learning communities that relies on curricular structures that link courses to aide students in deeper understanding and integration of academic material with five "core practices" for success: community, diversity, integration, active learning and reflection. ${ }^{3,4}$ According to Astin and Tinto, learning communities are defined by many factors of student involvement, including curricula, common interests and residential proximity to build a sense of group identity that is cohesive and unique to the group. ${ }^{5,6}$ Tinto asserts that a multi-faceted approach to learning communities in higher education encourages integration of diverse curricular and co-curricular experiences among students and enhances collaboration and the sense of individual belonging to the community. ${ }^{6}$

Shared classes and academic residential programs are two common methods for forming and studying learning communities that are beneficial to the individuals within them. LockwoodCooke, Davis, \& Hunt showed that at a large university, having an engineering learning community that links together students in specific courses leads to higher rates of completion for courses, fewer absences in those courses, higher self-rated gains in understanding the material, and increased retention within the major. ${ }^{2,7}$ Additionally, students sharing two or more interrelated courses was enough to have an effect on increasing retention for first-year engineering students. ${ }^{2}$ Other studies describe residential learning and living communities where students are housed together and share common academic interests as an effective method for increasing persistence, connection and satisfaction with the degree program. ${ }^{8,9,10}$

Our evolving definition of a learning community is built around both students' common GE+ curricula and interests as well as the impacts on their academic program satisfaction, university achievement and understanding of course material.

\section{Research Hypothesis}

With growing evidence that both formal and informal academic learning communities can improve the undergraduate education experience, and a desire to impact community and group identity between engineering students with diverse and multidisciplinary career interests, the new $\mathrm{GE}+$ degree program at CU Boulder understands that rigorous research into program activities and actions is essential to our students' satisfaction and retention. Given the diverse student experiences inherent in a degree program built around pervasive multidisciplinary curricular flexibility, this paper addresses the questions, "Is it possible to build community and scaffold group identity formation among students who spend little-to-no designated time together?" and "How can a sense of interconnectedness and community be created within a group that is intentionally diverse?"

\section{Methods}

\section{Setting for analysis}

In Fall 2013, the University of Colorado Boulder College of Engineering and Applied Science (CEAS) initiated a new bachelor's of science "General Engineering Plus" (or GE + ) degree program. The GE+ degree program design is threefold: providing an opportunity for students to 1) complete a design-rich engineering core; 2) complete a disciplinary emphasis in Aerospace, 
Mechanical, Architectural, Civil, Electrical or Environmental Engineering; and 3) complete a purposeful sequence of customizable electives either within or external to engineering (hence the “+”).

In addition to 16 credit hours of mathematics (Calculus I - Differential Equations) and 13-14 credit hours of science, the GE+ degree requires an engineering core ( 32 credit hours), discipline-based engineering electives ( $\sim 18$ credit hours) and a discipline-based capstone design course (4-10 credit hours) - totaling 30 credit hours of math/science and 54-60 credit hours of engineering. GE + majors also complete 18 humanities credit hours, and 12-15 credit hours of purposeful electives consisting of a student-chosen and previously contracted sequence of courses (which can be in many areas ranging from Economics to Environmental Policy). For example, a student might choose variations such as GE + Teach Engineering or GE + Engineering Management or GE + Spanish Language and Literature or GE + Business, etc.

The Teach Engineering "+" sequence includes a General Engineering degree coupled with secondary science or math teacher licensure. The GE + Teach Engineering program is designed to prepare graduates to earn secondary (grades 7-12) science or math teacher licensure and work in the engineering industry - providing a flexible and multi-faceted professional pathway. The BS GE + Teach Engineering degree program aims to integrate design-focused engineering curriculum, extensive science or math content, education pedagogy courses and student teaching.

Through the choice of an engineering disciplinary emphasis and a student-selected concentration, the General Engineering + degree program allows students to create a flexible and customizable engineering degree program. To date, no engineering degree program in our college offers the same level of curricular flexibility as the learner-centric GE + model. It is anticipated that students unsatisfied with the course-selection constrictions of our discipline-based, highly constrained engineering degree programs may find their way to this customizable, choice-rich option. Similarly, it is anticipated that this new degree program might also attract a new kind of student to engineering - students looking to become technically literate as undergraduates in preparation for careers in medicine, law, policy, business, etc.

Like other CU Boulder undergraduate engineering degrees, General Engineering Plus requires a total of 128 credit hours; however, some "+" options (such as secondary STEM teacher licensure) require more than 128 credit hours to complete both the engineering degree and an additional certificate, licensure, etc. Also like other CU Boulder undergraduate engineering degrees, the GE+ degree requirements include completion of required and elective courses with a minimum 2.25 grade point average, and all courses counting towards the required hours in engineering must have grades of $\mathrm{C}$ - or higher. The program will seek ABET accreditation under the General Engineering category after the first students graduate.

\section{Participants and Instrument Design}

A total of 45 students are currently enrolled in the GE+ program, including 26 first-year students and 19 students who transferred into the degree program. In fall 2014, 44\% $(n=20)$ of the GE+ students self-selected to complete a survey that aimed to understand student perceptions of the $\mathrm{GE}+$ major and community formation within the degree program. Students were offered a small incentive in the form of a "coffee card" for a free drink at the engineering center coffee shop. The respondents included $25 \%$ female $(\mathrm{n}=5)$ and $75 \%$ male $(\mathrm{n}=15)$ students, with their academic 
standings representative of the spectrum of experience: seven seniors, two juniors, five sophomores and six first-year students.

Administered via Qualtrics ${ }^{\circledR}$ Research Suite online survey software, the full survey consisted of 28 items, including 20 Likert-style ratings (see Appendix B). ${ }^{11}$ Survey questions queried attitudes towards professional engineering identity, community within the GE+ major, perceived differences between engineering majors, interests among students, value of attributes of the GE+ program and recommendations for future GE+ program support. Professional engineering identity questions were adopted from the Group Identification Survey in the Academic Pathways Study, which holds previous reliability and validity and includes items that address how a student defines him or herself as an engineer, public and personal regard for engineers, and the value that an individual places on belonging to a group of engineers. ${ }^{12}$

To augment the quantitative findings with qualitative perspective, two focus groups were held with GE+ students in September of 2014. Students were invited to participate in an hour-long focus group and pizza was served. Ten students participated in the focus groups. Seven of the focus group participants also completed the online survey. The first focus group was comprised of four GE+ students, including one second-year student and three first-year students. The second focus group included six GE+ students and consisted of one first-year, three sophomore and two junior students. Both focus groups had two female GE+ students in attendance. All nonfirst-year students transferred into GE+ from another engineering degree program at the university, with the exception of one student who transferred from CU Boulder's Molecular Cellular and Developmental Biology program. Focus group participants' engineering emphases included aerospace, mechanical, civil and environmental. The participants' "plus" concentrations included entrepreneurship, Teach Engineering, finance, business and a leadership program. During both focus groups, six main questions were asked of the students (see Appendix A for focus group questions), as well as clarifying or follow-up questions.

Surveys and focus groups for all participating students were conducted under the University of Colorado's Institutional Review Board (IRB) approval, reviewed annually by external and internal evaluators. Student responses are coded to protect participant identity.

\section{Analysis Methods}

Survey results included both quantitative and qualitative responses for analysis. Focus groups analysis are also described below.

\section{Quantitative}

The survey data was analyzed for missing values and data entry errors. Any missing values were examined for patterns of skipped responses. No student skipped more than one or two items in the survey, and there were no substantial relationships between skipped items. Demographic data, including gender and academic standing, was retrieved from the university database.

For likert-style questions, data was aggregated and analyzed into three categories (Strongly Agree and Agree; Neither Agree or Disagree; and Strongly Disagree and Disagree) for 
comparison purposes. Percentages and number of respondents are used to illustrate student attitudes towards community and engineering identity.

Subsequent questions asked students to group interests for program community building and value of program support into categories Highly Interested/Valuable; Somewhat Interested/ Valuable; and Not Interested/Valuable. These results are reported by percentages and number of respondents and are used to illustrate the most desirable activities that the GE+ team can use for program improvements. IBM SPSS statistical software package (version 22) and Excel were used for all analyses in this paper.

Additionally, the survey included three open-ended questions that probed descriptions of the $\mathrm{GE}+$ undergraduate students, differences between engineering majors, and recommendations to support the educational goals of GE+ students. The text responses were analyzed for repeated terms and ideas and are reported below in percentage of similar responses.

\section{Qualitative}

Focus group analysis followed a simple systematic method for analyzing narratives described in the literature. ${ }^{13}$ The focus group scripts were transcribed independently by the authors, who determined ten thematic categories that were mentioned throughout each of the focus groups.

Next, the authors agreed on simplified statements (codes) to represent each category as well as a concise definition of each (see Table 1). Since the text was not going to be entered into a defined computer program for comparison to future focus groups, colors were assigned to each code as a category symbol and for ease of coding copies of the transcripts. Thus, each general theme in the text was given a code and definition, as well as a color to symbolize each code.

Table 1. Codes and Definitions for Analysis of Focus Group Transcripts

\begin{tabular}{|l|l|}
\hline \multicolumn{1}{|c|}{ Code (category) } & \multicolumn{1}{c|}{ Definition } \\
\hline Definition of GE+ & What is GE+? \\
\hline GE+ Identity & I am/not a GE+ student \\
\hline Motivation & $\begin{array}{l}\text { To choose/transfer to GE+ } \\
\text { Why did students choose GE+ or transfer to GE+? }\end{array}$ \\
\hline Pathways \& Curriculla & $\begin{array}{l}\text { Logistics: } \\
\text { Pathways "to" and "through" GE+ } \\
\text { What concentration and emphasis paths are students choosing } \\
\text { within GE+? }\end{array}$ \\
\hline $\begin{array}{l}\text { Perceptions of GE+ and } \\
\text { other majors }\end{array}$ & $\begin{array}{l}\text { Internal and external; from outside looking in and inside } \\
\text { looking out } \\
\text { Perceptions of other majors }\end{array}$ \\
\hline
\end{tabular}




\begin{tabular}{|l|l|}
\hline GE+ Community & $\begin{array}{l}\text { What exists now? } \\
\text { What do students want it to be? }\end{array}$ \\
\hline School/Life Balance & $\begin{array}{l}\text { Or lack of balance } \\
\text { What works and what does not? }\end{array}$ \\
\hline Future & Students' personal hopes, dreams and fears about the future \\
\hline GE+ Program Pride & Praise or justifications for GE+ \\
\hline $\begin{array}{l}\text { Concerns/Uncertainty/ } \\
\text { Suggestions for GE+ }\end{array}$ & Concerns about the program and suggestions for improvement \\
\hline
\end{tabular}

Three independent readers (outside of the authors) read and color-coded the transcripts according to the ten code themes. Relevant information was classified by giving each fragment of colorcoded transcript a unique identification number and entered into columns and rows in a spreadsheet for easy comparison and indexing of individual coder's responses. The inter-rater reliability was determined through visual comparison of lines of text that each reader coded into the ten themes. Reported results reflect the themes with agreement by all three readers.

\section{Results}

Survey and focus groups results showed that a variety of factors are used to define community and professional identity with the GE+ program.

\section{Survey Results}

The first survey question asked students to rate 20 statements around learning communities and identity on a five-point Likert scale of Strongly Disagree, Disagree, Neither Agree or Disagree, Agree, or Strongly Agree. The statements were given identification codes for ease of analysis. The statements and codes can be found in Tables 2 and 3.

Table 2. Codes and GE+ Survey Community Statements Used for Analysis

\begin{tabular}{|l|l|}
\hline \multicolumn{1}{|c|}{ Code } & \multicolumn{1}{c|}{ GE+ Community Statement } \\
\hline Comm1 & There is a GE+ community. \\
\hline Comm2 & I am a part of the GE+ community. \\
\hline Comm3 & I know other GE+ students. \\
\hline Comm4 & I spend time with other GE+ students (either within or outside of class). \\
\hline Comm5 & I am involved with the GE+ program. \\
\hline Comm6 & I interact with GE+ faculty. \\
\hline Comm7 & I plan to complete a degree in engineering. \\
\hline
\end{tabular}




\begin{tabular}{|l|l|}
\hline Comm8 & I plan to complete a degree in GE+. \\
\hline Comm9 & I am a welcome member of the GE+ community. \\
\hline Comm10 & Experiences in GE+ have given me a positive impression of engineering. \\
\hline Comm11 & Differences exist between GE+ students and other engineering majors. \\
\hline
\end{tabular}

Table 3. Codes and GE+ Survey Identity Statements Used for Analysis ${ }^{12}$

\begin{tabular}{|l|l|}
\hline \multicolumn{1}{|c|}{ Code } & \multicolumn{1}{c|}{ GE+ Identity Statement } \\
\hline ID1 & I can succeed in the engineering curriculum. \\
\hline ID2 & I am good at designing things. \\
\hline ID3 & I know what an engineer does. \\
\hline ID4 & I am interested in taking more engineering courses. \\
\hline ID5 & I am interested in taking more non-engineering courses. \\
\hline ID6 & I am interested in taking more engineering courses outside of my major. \\
\hline ID7 & I am interested in multiple different kinds of fields. \\
\hline ID8 & I know (roughly) what I want to do once I leave college. \\
\hline ID9 & I want to give back to the community. \\
\hline
\end{tabular}

A stacked bar chart visually compares the percent of students' response on a Likert-scale of 1-5 for each of the statements. The chart for learning communities is in Figure 1.

Noticeable in the chart is that no students strongly disagreed with any of the GE+ community statements. The largest agreement (combines Agree and Strongly Agree) were for the statements, "I plan to complete a degree in engineering" (Comm7; 85\% agreement) and "I plan to complete a degree in GE+" (Comm8; 80\% agreement). Other items with high agreement include, "I know other GE+ students" (Comm3; 75\% agreement), "I interact with GE+ faculty" (Comm6; 70\% agreement), "I am a welcome member of the GE+ community"(Comm9; 75\% agreement), and "Experiences in GE+ have given me a positive impression of engineering"(Comm 10; 75\% agreement).

The lowest agreement is in "I spend time with other GE+ students (either within or outside of class)."(Comm4; 35\% agreement), and "I am a part of the GE+ community" (Comm2; 45\% agreement). This evidence suggests that GE+ students are positive in their ability to complete an engineering degree and that GE+ is a welcoming program. However they have not yet started to spend time with other GE+ students or view themselves as part of the GE+ community. 
Figure 1. Percent Agreement towards GE+ Community Survey items

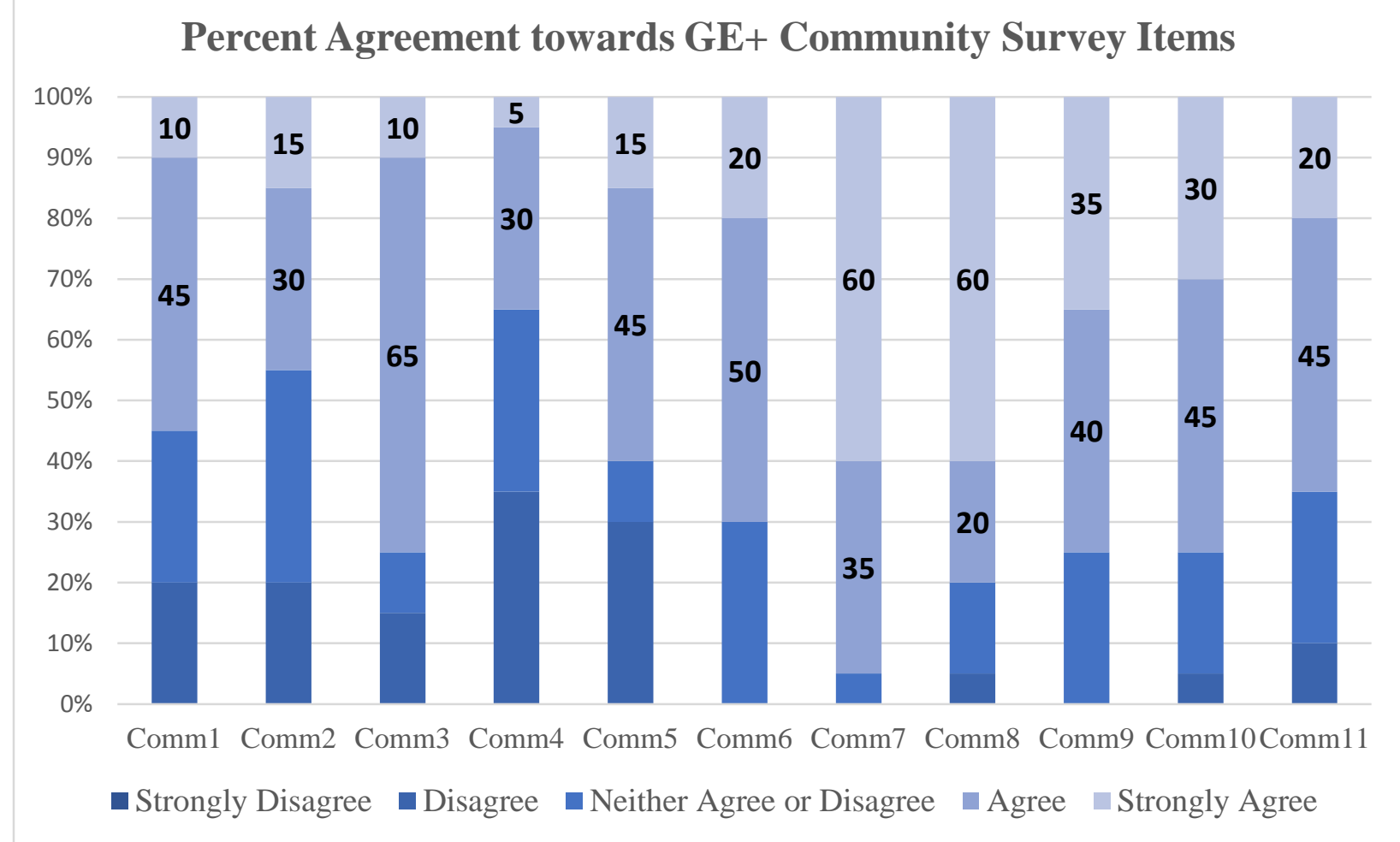

The comparisons of attitudes on GE+ engineering identity is shown in Figure 2. For this set of questions as well, no students strongly disagreed with any of the GE+ identity statements.

The largest agreement (combines Agree and Strongly Agree) is for the statement, "I am interested in taking more non-engineering courses" (ID5; 100\% agreement). Other items with high agreement include, "I am good at designing things" (ID2; 90\% agreement), "I know what an engineer does" (ID3; 90\% agreement), and "I am interested in taking more engineering courses" (ID4; 90\% agreement). While these statements had the highest agreement among GE+ students, all of the nine identity items had a majority agreement, indicating that the GE+ students are already confident in their connections to, and identity with, engineering. Perhaps choosing a customized, unconventional, and/or new engineering degree takes a higher than average confidence to begin with? We have not yet further probed this question. 
Figure 2. Percent Agreement with GE+ Identity Survey Items

\section{Percent Agreement with GE+ Identity Survey Items}

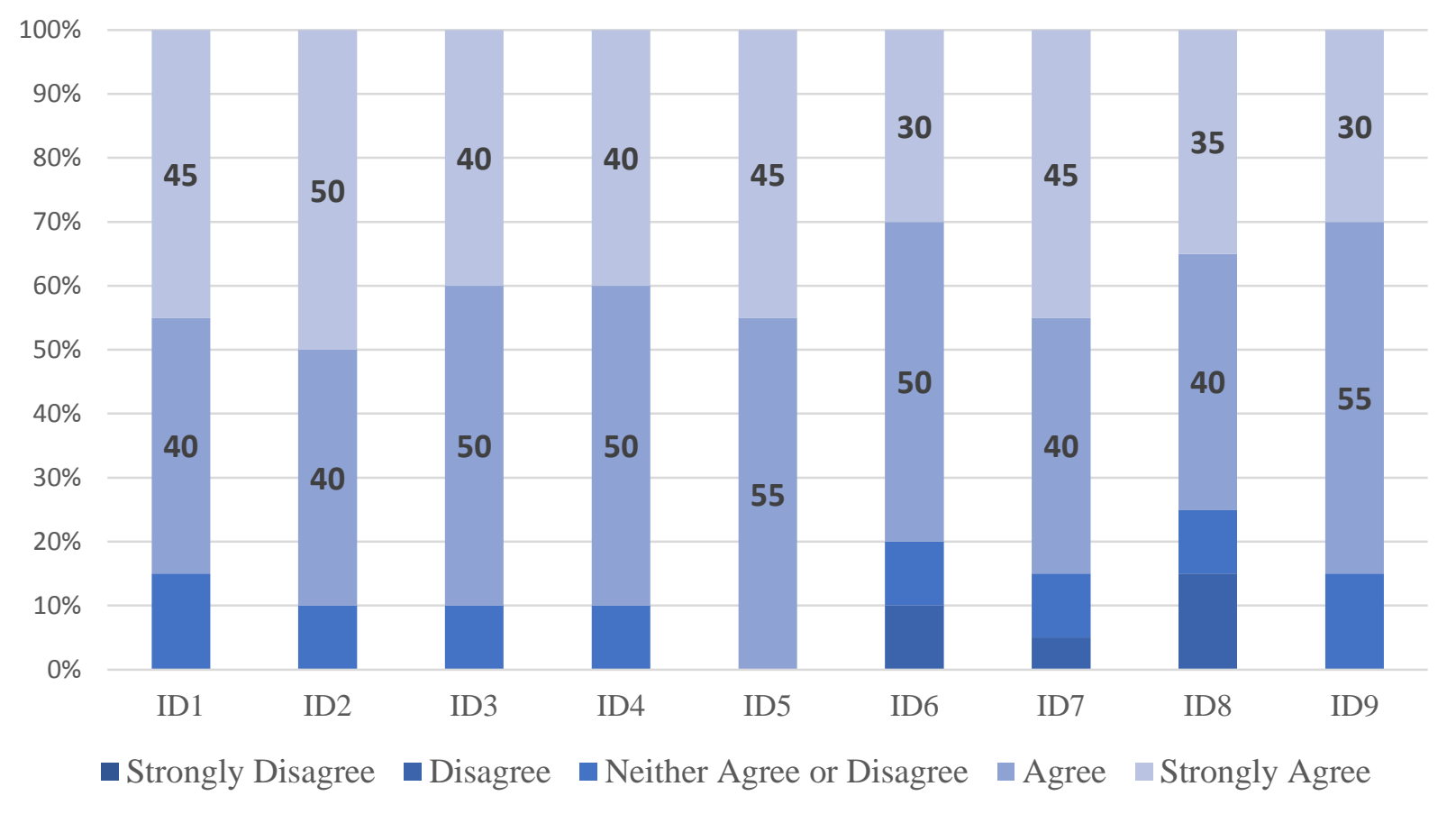

Students were also asked to group both personal interests (to inform future learning community building events) by Highly Interested, Somewhat Interested, and Not Interested, and attributes that would be valuable in the GE+ community by Highly Valuable, Somewhat Valuable, and Not Valuable. Results from the top activities (where the majority of students ranked as "highly interested" or "highly valuable" are listed below in Tables 4 and 5.

Table 4. Interests of GE+ Students for Community Building

\begin{tabular}{|l|c|c|}
\hline \multirow{2}{*}{$\begin{array}{c}\text { Top Seven Interests for } \\
\text { Community Building }\end{array}$} & \multicolumn{2}{|c|}{ Highly Interested } \\
\cline { 2 - 3 } & $\mathbf{n}$ & \% \\
\hline Design & 16 & 80 \\
\hline Leadership & 14 & 70 \\
\hline Skiing or Snowboarding & 13 & 65 \\
\hline Hiking & 13 & 65 \\
\hline Sciences & 11 & 55 \\
\hline Food & 11 & 55 \\
\hline Project Management & 11 & 55 \\
\hline
\end{tabular}


Table 5. Attributes of Value for the GE+ Community

\begin{tabular}{|l|c|c|}
\hline \multirow{2}{*}{$\begin{array}{c}\text { Top } 6 \text { Attributes Valuable for } \\
\text { GE+ Community }\end{array}$} & \multicolumn{2}{|c|}{ Highly Valuable } \\
\cline { 2 - 3 } & $\mathbf{n}$ & $\%$ \\
\hline Faculty Accessibility & 15 & 75 \\
\hline Career Counseling & 15 & 75 \\
\hline Upperclass Student Mentoring & 14 & 70 \\
\hline Common Classes & 11 & 55 \\
\hline Peer Tutoring & 10 & 50 \\
\hline Program Get-Togethers & 9 & 45 \\
\hline
\end{tabular}

As can be seen, GE+ students are interested in community-building activities that help increase professional skills in design and leadership or get them socially engaged with their peers in the outdoors. They also want more from the GE+ program in terms of informing their postgraduation futures through purposeful interactions with faculty, upper-class students and career counseling.

These results are all supported by several open-ended text response questions in the survey. Three text responses were asked of students: "Please describe the differences you see (between GE+ and other majors)," "How would you describe the GE+ major and people," and "What would you recommend GE+ does to better support you and your educational goals?"

Please describe the differences you see (between GE+ and other majors). 80\% ( $\mathrm{n}=16)$ of student respondents identified GE+ students as being different from other engineering majors because the program has more diverse interests. Students wrote:

"The students in GE+ have more interests in other majors, such as teaching, business, art, language, and more. They can see themselves in a future in engineering and also something completely different."

"GE+ students chose GE+ because it offered breadth, a vision into other fields and disciplines. Therefore GE+ students seem to better embrace the inherent subtlety of the world. They seem better accustomed to bringing together people and technical skills."

Additionally, 25\% of respondents indicated that GE+ students have more positive personality traits than other engineering majors.

"GE+ students thus far seem overall less like the miserable robots than so many engineering students can sometimes become."

Another $38 \%$ of respondents mentioned that GE+ students are set apart because they have "choice" or "freedom." 
How would you describe the GE+ major and people? Of the 19 students who responded to this question, 58\% mentioned the diverse interests of GE+ students. For example, one respondent wrote, "The GE+ major is for people who are curious in different fields and want to diversify and culture their minds." Another 63\% of students mentioned positive personality traits associated with GE+ students, such as "fun," "inviting," "passionate," "outgoing," "friendly," or even "a little less 'gloomy' than the other engineering majors. We aren't as focused on the engineering salary and are more focused on the people around us."

Just over $20 \%$ of the students mentioned the flexible GE+ curriculum in their descriptions, and over $97 \%$ of the comments were positive towards the GE+ major and people, indicating substantial GE+ pride, which was also demonstrated in the following focus groups.

Student responses for the third text-response question regarding student recommendations for the GE+ program to better support students and their educational goals are discussed in the "Recommendations for future work" section below.

\section{Focus Group Results}

As expected, the focus groups discussions delved deeper into the thinking of the GE+ students than the open-ended survey questions allowed, including discussions around pathways to and through GE+, school/life balance, students' personal hopes, dreams and fears about the future, and pride in the GE+ program. Of the 10 themes that emerged from the two GE+ focus groups (See Table 1), two themes were of particular interest to this study: GE+ Identity and GE+ Community.

GE+ Identity. As detailed in Table 1, the GE+ Identity theme was clarified to raters as dialogue around students' self-identification (or non-identification) as GE+ students, "I am a GE+ student" or "I am not a GE+ student."

Two raters found no instances of GE+ Identity discussion in the first focus group, while one rater categorized only one short comment as GE+ Identity discussion. There was therefore no consensus between raters on any GE+ Identity discussion for the first focus group. Conversely, all raters found the second focus group discussed GE+ identity multiple times. This notable difference in GE+ identity discussion is particularly interesting considering that three out of the four students in the first focus group were first-year students, while only one out of the six students in the second focus group was a first-year student. Thus, the increased discussion around GE+ Identity in the focus group with students farther along in their undergraduate careers could be an indicator that first year students had not yet identified with the GE+ major in their first semester.

The second focus group discussed a shared experience of the difficulty of self-identifying as part of a new, unconventional engineering degree program that peers may not have heard of and/or may not understand. One student described the "weird group dynamic [in the engineering college] where everyone introduces themselves [by major], like, 'Hi, I'm so-and-so, and I'm studying such-and-such.'" Each of the six students in the second focus group indicated that in those social situations they elected to self-identify by their engineering emphasis (aerospace, architectural, civil, electrical, environmental, or mechanical) instead of announcing themselves 
as GE+ students. Based on student discussion, this tendency seems rooted in a reluctance to take a social risk and draw attention to oneself with a lengthy explanation of the GE+ program for peers who haven't heard of it. One student described announcing himself as a GE+ student as "let me tell you five minutes about myself. That's sort of what it takes for GE+." Another student said, "Maybe I'm part of the problem. When there's 10 engineers in a new class, and everyone's doing electrical and mechanical, I just say I'm mechanical for ease, I guess."

$G E+C o m m u n i t y$. Each of the three raters coded multiple parts of both focus group results as $\mathrm{GE}+$ Community discussion. This theme was detailed to raters (Table 1) as "What [GE+ community] exists now? What do students want [the GE+ community] to be?"

First-year students in the first focus group each indicated that they knew of other GE+ students from an orientation day and had seen each other in class. One student said she had "hung out outside of class" with other GE+ students, and two of the students in the focus group lived on the same dormitory hall, so they were "familiar face[s]."

The sophomore in the first focus group had transferred into the GE+ degree program in its inaugural year before there was a first year cohort and had not met any other GE+ students until the focus group.

Several students from the second focus group also said they knew of other GE+ students from orientation day, while other students who transferred into the program had the shared experience of not knowing other GE+ students and desired more community in the degree program. A junior student who transferred into the GE+ degree program stated:

"I think it would be cool to have more stuff to get to know people, because I would say I've had to justify my [decision to choose GE+] more to, say, to my parents or my other engineering friends...it's a new thing. It makes sense that people don't necessarily know why you would have chosen to do it. So having known more people either before I made this decision or after would have helped me to get more perspectives on making the mechanical versus [GE+ mechanical emphasis] decision."

The second focus group discussed the challenge of forming a GE+ student community when they are often not in the same classes due to the multidisciplinary nature of the degree program, unlike engineering students enrolled in traditional engineering majors in the college. One student stated:

"I feel like engineers bond a lot over being in the same degree. You've taken the same classes, you know which stuff was hard. It's easy to bond with someone if you have something like that in common. We all don't have the same degree in common. I don't think that makes it harder, but it certainly doesn't make it easier, whereas I know everyone in my material science class is a mechanical engineer. They have to be."

Participants in both focus groups expressed interest in more community within the GE+ major, and students in the second group strongly requested events for the GE+ students that could help them connect with each other more easily outside of class. As one junior student stated, "[GE+] is such a small community right now, I think there's a lot of potential for it to be a close community." 


\section{Limitations of the study}

The findings of these analyses must be considered within the limitations of the study. The data presented in this study is self-reported, and therefore inherently subject to researcher bias. Each author of this paper is in some way involved in the GE+ degree program; no impartial researchers took part in this study.

Inter-rater reliability for the focus group study was limited. For each of the 10 themes that emerged from the two focus groups, the raters' respective coding was sometimes in agreement and other times in disagreement.

A total of 10 students participated in the focus groups, representing $23 \%$ of GE+'s total student population, while the 20 survey respondents represented $44 \%$ of enrolled GE+ students. Though pleased with the focus group participant and survey response rates, we acknowledge that these are small sample sizes. Compounding the matter of small sample size is the fact that the GE+ degree program is brand new, so no longitudinal data exists (yet) on identity and community formation in the program. As such, the findings put forth in this paper instead provide a single snapshot of these themes in the program's earliest stages, with the pioneer students.

The "new-ness" of the program stands to impact perceptions of the GE+ degree program, including self-perceptions of students in the major and potential misconceptions of what the degree program is or is not. It takes time for a program to develop an identity and a place in an engineering college. Certainly each of these things has bearing on student identity formation as well as the GE+ community formation. As program marketing and information available to students advance, we anticipate that the program identity and community will shift and change.

\section{Key findings and discussion}

Our findings suggest that it is possible to build community and scaffold group identity formation among students with a common major with few overlapping classes. The results from this study reflect the early stages of forming the GE+ learning community. Students are still finding each other and seek more contact with one another.

The online survey indicates that GE+ students are confident in their abilities to succeed in engineering. They highly identify with engineering as a profession and have pride in the GE+ program, touting diverse interests of students and working with other fun and passionate people like themselves. However, the GE+ students do not feel well connected; they have not spent significant time with other students in the program and are struggling to view themselves as part of the GE+ learning community.

A strong desire exists amongst some GE+ students for a closer, more established learning community. This desire was especially prevalent amongst sophomore and junior students who transferred into the program from another engineering major. These same students also expressed a more developed identity as GE+ students. 
It appears that first-year students identify less as GE+ students, which is perhaps a reflection that first-year students must first adjust to the college experience as a whole and develop a personal identity as a college student before they can begin exploring an identity within a given major.

Findings also suggest that self-identifying to this new, atypical GE+ engineering major in group settings with peers from more conventional engineering degree programs can be socially risky. Though students overwhelmingly expressed pride in the GE+ program through their qualitative survey responses and focus group discussions, they are less inclined to express this pride publicly with peers in the engineering college.

Lastly, GE+ students see differences between themselves and their peers in other engineering majors. Many describe themselves as a group with diverse interests, a reflection of the multidisciplinary nature of the degree program.

\section{Recommendations for future work}

Results from the analyses presented in this paper will inform the future work of GE+ faculty and (we hope) other faculty negotiating multidisciplinary programs to meet the expressed needs and desires of their students, with the aim of continuing to foster learning community development. Survey results revealed that the GE+ students are interested in both academic and social community-building opportunities. The students also desire more meaningful interactions with faculty and upper-class students, as well as additional career counseling in anticipation of graduating from such a multidisciplinary program.

Fifteen GE+ students (34\%) responded to the open-ended survey question that requested recommendations for the GE+ program to "better support [them] and [their] educational goals." Two of those student respondents were happy with the program "as-is," four students requested help from the program with finding job opportunities, five had specific degree curriculum recommendations, and six expressed a desire to know more students and faculty in GE+. Additionally, students requested social, food-oriented gatherings for GE+ students that would encourage connections in and to the degree program.

The GE+ faculty and staff held the first such gathering with an ice cream party in November and a Pi Day party in March. Additionally, a team of GE+ students have taken the lead on organizing a student-run community event in April. The GE+ program plans to continue holding similar events on a somewhat regular basis. We hope that these and future events contribute to a sense of interconnectedness in the growing GE+ community.

Faculty and researchers in the GE+ program will continue collecting formal and informal qualitative and quantitative data, ultimately allowing for a longitudinal look at identity and learning community development in this novel multidisciplinary engineering degree program. We are hopeful that this commitment to continuously gather data coupled with responsiveness and timely program improvements will encourage a strong sense of community and group identity in the degree program. We plan to also track mid- to long-term data about graduates of the program to determine if identity and community continue after graduation. 
We believe it is possible to build a strong learning community and support group identity formation between students within a group that is intentionally multidisciplinary. Our students already have some identity with the engineering profession and a determination to succeed in a program that supports individual passions. We anticipate that common core courses, interests, and intentional community-building gatherings will provide the building blocks for a connected GE+ learning community. We will continue to listen to our students and create academic and social opportunities for all of us to grow the GE+ learning community together.

\section{References}

[1] Watford, B. A., \& Artis, S. (2004). "Hypatia: A Residential Program for Freshman Women in Engineering," Proceedings, ASEE Annual Conference, Salt Lake City, UT.

[2] Lockwood, P. R., \& Hunt, E. M. (2013). "Engineering Learning Communities,” Proceedings, ASEE Annual Conference, Atlanta, GA, June.

[3] Reviewed Work: Learning Communities: Reforming Undergraduate Education by B. L. Smith, J. MacGregor, R. S. Matthews, F. Gabelnick. Review by: Nancy S. Shapiro, The Journal of Higher Education, Vol. 77, No. 3 (May - Jun., 2006), pp. 550-553

[4] Kellogg, K. (1999). Learning Communities. Washington, DC: ERIC Clearinghouse on Higher Education. Retrieved from www.eric.ed.gov. January 2014.

[5] Astin, A. W. (1984). Student Involvement : A Developmental Theory for Higher Education. Journal of College Student Development, (July), 518-529.

[6] Tinto, V. (2003). Learning Better Together : The Impact of Learning Communities on Student Success. Higher Education Monograph Series, Syracuse University, (2003-1), 1-8.

[7] P. Lockwood-Coke, F. Davis, E. Hunt. (2013). "Engineering Learning Communities: Relationships, Results, and Retention," Proceedings, ASEE Annual Conference, Vancouver, BC.

[8] M. Degley Falls, M. Georgiopoulos, C. Young, "Influencing Sense Of Community In A Stem Living-Learning Community: An Nsf Step Funded Project," American Society for Engineering Education, 2010.

[9] Harms, P. C., Mickelson, S. K., Brumm, T. J., Harms, P. C., Mickelson, S. K., \& Brumm, T. J. (2001). “Using a First-Year Learning Community to Help Meet Departmental Program Objectives in Agricultural \& Biosystems Engineering Program Objectives in Agricultural \& Biosystems Engineering," Proceedings, ASEE Annual Conference, Albuquerque, NM, June.

[10] Vasko, T. J. (2012). "Comparison of a First-Year-Experience Course with and without a Living-LearningCommunity Arrangement," Proceedings, ASEE Annual Conference, Atlanta, GA, June.

[11] Qualtrics. [Online] November 2014. http://qualtrics.com/.

[12] Chachra, D., Olin, F. W., Kilgore, D., Loshbaugh, H., Mccain, J., and H. Chen (2008). "Being and Becoming: Gender and Identity Formation of Engineering Students," Proceedings, ASEE Annual Conference, Pittsburgh, PA, June.

[13] Gorden, Raymond (1992). Basic Inteviewing Skills. Itasca, IL: F. E. Peacock. 


\section{Appendix A: GE+ Focus Group Questions}

- Why did you choose GE+ over another engineering degree program at (Insert University Name) like Mechanical, Civil, Aerospace, etc.?

- How do you feel about the GE+ curricula?

- What have you done with other people in GE+?

- How would you describe the GE+ major and people? What's the feeling you get from it?

- Do you think there are any differences between GE+ and other engineering majors overall?

- Are you interested in pursuing any interests outside of engineering during college? Why and how? 


\section{Appendix B: GE+ Community Survey}

Which emphasis are you most interested in pursuing within your GE+ degree?

Which concentration are you most interested in pursuing within your GE+ degree?

Do you think there are any differences between GE+ and other engineering majors?

Please indicate how much you agree with the following statements: (5 point Likert)

1. There is a GE+ community.

2. I am a part of the GE+ community.

3. I know other GE+ students.

4. I spend time with other GE+ students (either within or outside of class).

5. I am involved with the GE+ department.

6. I interact with GE+ faculty.

7. I plan to complete a degree in engineering.

8. I plan to complete a degree in GE+.

9. I am a welcome member of the GE+ community.

10. Experiences in GE+ have given me a positive impression of engineering.

11. Differences exist between GE+ students and other engineering majors.

12. I can succeed in the engineering curriculum.

13. I am good at designing things.

14. I know what an engineer does.

15. I am interested in taking more engineering courses.

16. I am interested in taking more non-engineering courses.

17. I am interested in taking more engineering courses outside of my major.

18. I am interested in multiple different kinds of fields.

19. I know (roughly) what I want to do once I leave college.

20 . I want to give back to the community.

What have you done with other people in GE+? (radial buttons). Options: attended class, hang out, participate in clubs, other extracurricular activities, roomates, studied in groups, lived in the dorms, other (please specify), nothing)

How would you describe the GE+ major and people (open-ended; up to 150 characters)?

Please group and rank the following interests with highest interest on top and least interest on bottom. (Drag and drop; highly interested/somewhat interested/not interested). Options: Business, Other types of engineering, Design, Leadership, Project Management, Writing, Reading, Languages, Music, Art, History, Sciences, Different clubs, Skiing/ snowboarding, Hiking, Rock climbing, Food, Yoga, Video games, Sports, Other

Please group and rank which attributes would be valuable to you in the GE+ community with most valuable on top and not valuable on bottom. (Drag and drop; Valuable/Somewhat valuable/Not valuable) Options: Peer tutoring, Upperclass student mentoring, Common classes, Career counseling, Program get-togethers, Faculty accessibility, Other

What would you recommend GE+ does to better support you and your educational goals? 